University of Nebraska - Lincoln

DigitalCommons@University of Nebraska - Lincoln

Agronomy \& Horticulture -- Faculty Publications

Agronomy and Horticulture Department

1958

Rapid Tests for Free and Bound Coumarin in Sweetclover

Herman J. Gorz

United States Department of Agriculture

Francis A. Haskins

University of Nebraska-Lincoln, fhaskins@neb.rr.com

Follow this and additional works at: https://digitalcommons.unl.edu/agronomyfacpub

Part of the Plant Sciences Commons

Gorz, Herman J. and Haskins, Francis A., "Rapid Tests for Free and Bound Coumarin in Sweetclover" (1958). Agronomy \& Horticulture -- Faculty Publications. 272.

https://digitalcommons.unl.edu/agronomyfacpub/272

This Article is brought to you for free and open access by the Agronomy and Horticulture Department at DigitalCommons@University of Nebraska - Lincoln. It has been accepted for inclusion in Agronomy \& Horticulture -Faculty Publications by an authorized administrator of DigitalCommons@University of Nebraska - Lincoln. 


\title{
Rapid Tests for Free and Bound Coumarin in Sweetclover
}

\author{
H. J. Gorz and F. A. Haskins ${ }^{2}$
}

\section{SYNOPSIS}

Two qualitative fluorometric methods are described. The tube test, in which scoring is based upon visual comparison of the fluorescence of test solutions with the fluorescence of standards, was more reliable than the paper test. The paper test should be used primarily for rapid, initial screening of large populations.

$\mathrm{R}^{\mathrm{n}}$ ELIABLE qualitative tests for free and bound coumarin $\mathbf{R}_{\text {are of extreme importance in achieving maximum eff. }}$ ciency in the development of strains of sweetclover low in coumarin content. In addition to being useful in the mass screening of large populations, rapid tests also are of value in genetic studies involving the two main pairs of alleles, $C u / c u$ and $B / b$, which appear to condition content and form of coumarin in the plant $(2,4)$. If these genes are to be used as genetic markers, it is necessary that the qualitative test for coumarin permit the separate detection of both the free and bound forms, so that both allelic pairs can be identified. Rapid fluorometric methods proposed by Ufer (6), Slatensek and Washburn (5), White et al. (7), and Goplen et al. (3) permit the distinction of coumarincontaining plants from those low in coumarin content but do not provide information concerning the form in which the coumarin is present. Use of Smith's $\mathrm{s}^{3}$ qualitative method based on the colorimetric determination of Clayton and Larmour (1) permits the detection of free coumarin, but coumarin-deficient and bound-coumarin plants are indistinguishable with this method. Two rapid fluorescence tests are described in the present paper and data supporting the reliability of the methods are presented. Both methods provide for the separate detection of free and bound coumarin.

\section{MATERIALS}

Samples were obtained from plants grown from seed in the greenhouse and from second-year plants grown in the field. The greenhouse-grown material consisted of 365 plants approximately equally distributed among 13 segregating $S_{2}$ lines all derived from a single $S_{o}$ plant that was heterozygous for the two main allelic pairs known to condition coumarin content in sweetclover. The seedlings were grown in flats and were sampled when all plants had begun flowering. Plants sampled in the field consisted of heterozygous breeding lines as well as check-rows containing plants which were either coumarin-deficient or which contained bound coumarin or both free and bound coumarin. Sampling was done at a stage of maturity just prior to the appearance of floral buds. In all cases, samples for both the tube and the paper test were obtained from the same leaflet, selected from the last fully $\mathrm{ex}$. panded leaf at the apex of the plant. ${ }^{+}$

${ }^{1}$ Cooperative investigations of the Crops Research Division, A.R.S., U.S.D.A., and the Nebraska Agr. Exp. Sta., Lincoln, Nebr. Published with the approval of the Director as Paper No. 831, Journal Series, Nebraska Agr. Exp. Sta. Received September 9, 1957.

"Research Agronomist, Crops Research Division, A.R.S., U.S.D.A., and Associate Agronomist, Nebraska Agr. Exp. Sta., respectively. The assistance of John Hermanussen in certain phases of this work is gratefully acknowledged.

${ }^{3}$ Personal communication from $W$. K. Smith of the University of $\mathrm{W}$ isconsin.

${ }^{7}$ Brink, V. C. The content, distribution, and some metabolic aspects of coumarin in sweetclover (Melilotus alba Desr.). Unpub. Ph.D. Thesis. University of Wisconsin. 1941.
All ultraviolet treatments were imposed with a Gates M.R. 4 Laboratory Lamp in which the T.F. 8 tube was installed. The energy peak of this tube is near 3,600 angstroms. Coumarin and $\mathrm{NaOH}$ (reagent grade) were obtained from the Eastman Kodak Co., and the J. T. Baker Chemical Co., respectively. A surface active agent, Amine 220 (obtained from the Carbide and Carbon Chemicals Company), was used in the tube method. Pyrex culture tubes in the tube method and Whatman No. 1 filter paper in the paper method were used exclusively.

\section{PROCEDURE AND RESULTS The Tube Method}

The duration of irradiation and of autoclaving in water and in base, as described in this method, are based upon data presented in the quantitative assay method described by Haskins and Gorz (4).

Samples, each consisting of a portion of leaflet approximately $25 \mathrm{sq} . \mathrm{mm}$. in area, were removed and placed in individual $10 \times 75 \mathrm{~mm}$. Pyrex culture tubes. Samples held in dry tubes for as long as 6 hours appeared unchanged with respect to content of free and bound coumarin. Within 4 hours after sampling, sample tubes were brought to the laboratory, where $1 \mathrm{ml}$. of water containing $100 \mathrm{ppm}$. (volume) of Amine 220 was added to each sample with an automatic syringe. Addition of the Amine 220 aided in submerging the leaf sample and did not interfere with the subsequent fluorescence scoring. After gentle shaking of each rack, samples were checked to see that all were submerged, after which they were autoclaved for 15 minutes at 15 psi. to extract coumarin from the leaf tissue. Following this extraction treatment, the leaflet tissue samples were removed from the tubes with a small, bent scalpel which was rinsed in distilled water between samples. One $\mathrm{ml}$. of $5 \mathrm{~N} \mathrm{NaOH}$ was then added to each extract with an automatic syringe. The spurting action of the syringe adequately mixed the contents of the tube. After irradiation for 15 minutes under ultraviolet light, each sample was given a score of 1 to 5 by comparing the fluorescence of the sample with a set of standards having known concentrations of coumarin. The standards were arranged in order of concentration in a rack with spaces for the insertion of test solutions between the standards. Coumarin equivalence values and approximate coumarin contents of leaf tissue corresponding to scores 1 to 5 , are shown in table 1.

Table 1.-Coumarin equivalence values and approximate coumarin contents of leaf tissue corresponding to scotes 1 to

5. The calculated levels of coumarin assume a sample weight (dry basis) of $0.5 \mathrm{mg}$. which is reasonably close to the weight of the samples used.

\begin{tabular}{cllll}
\hline Score & $\begin{array}{c}\text { Coumarin equivalence of } \\
\text { solution }\end{array}$ & \multicolumn{2}{c}{$\begin{array}{c}\text { Approximate level of } \\
\text { coumarin in leaf }\end{array}$} \\
\hline & $\gamma / \mathrm{ml}$. & $\gamma / \mathrm{ml}$. & \% of dry weight \\
1 & $\geqq 0$ & $<0.05$ & $\geqq 0$ & $<0.02$ \\
2 & $\geqq 0.05$ & $<0.25$ & $\geqq 0.02$ & $<0.10$ \\
3 & $\geqq 0.25$ & $<0.625$ & $\geqq 0.10$ & $<0.25$ \\
4 & $\geqq 0.625$ & $<1.25$ & $\geqq 0.25$ & $<0.50$ \\
5 & $\geqq 1.25$ & & $\geqq 0.50$ & \\
\hline
\end{tabular}


After the basic solutions had been scored for fluorescence, they were autoclaved for 30 minutes at 15 psi., cooled, re-irradiated with ultraviolet for 15 minutes and scored a second time using the same set of standards.

Scores obtained before autoclaving the extracts in base are a measure of the content of free coumarin, scores obtained after autoclaving are a measure of total coumarin, and comparison of the "before" and "after" scores on the same sample affords a measure of bound coumarin content.

Accuracy of the visual scoring used in the tube method was tested as follows: 33 test solutions with known concentrations of coumarin in $2.5 \mathrm{~N} \mathrm{NaOH}$ were prepared, and numbers from 1 to 33 were assigned at random to the solutions. Two-ml. portions of the solutions were transferred to individual $10 \times 75 \mathrm{~mm}$. Pyrex culture tubes. These tubes were arranged numerically in a rack and, together with a set of standards described in table 1, were irradiated with ultraviolet for 15 minutes. The solutions were then scored by four persons, working independently. Of the 4 scorers, 3 had had previous experience with this method. As shown in table 2, some variation in scoring ability was found among the four persons but none of the errors was of such magnitude as to be considered serious in a qualitative test of this type. Interestingly, the best scoring record was achieved by the person with no previous experience in scoring fluorescence. In another experiment of this type, essentially similar results were obtained.

On the basis of the score limits listed in table 1 and the coumarin contents which have been found for the low-, bound-, and free-coumarin phenotypes of sweetclover (Haskins and Gorz (4), and unpublished results), the following score limits were set up for the three phenotypes:

Table 2.-Accuracy of scoring of solutions containing known concentrations of coumarin.

\begin{tabular}{|c|c|c|c|c|c|c|}
\hline \multirow{3}{*}{$\begin{array}{c}\text { Coumarin concentration } \\
\text { of solution } \\
\gamma / \mathrm{ml} .\end{array}$} & \multicolumn{6}{|c|}{ Fluorescence score } \\
\hline & \multirow[t]{2}{*}{ Expected } & \multicolumn{5}{|c|}{ Observed by scorer } \\
\hline & & $\mathrm{a}$ & $\mathrm{b}$ & $\mathrm{c}$ & & d \\
\hline $0^{*}$ & 1 & 1 & 1 & 1 & & 1 \\
\hline 0.01 & l & 1 & I & 1 & & 1 \\
\hline 0.02 & 1 & 1 & 1 & 1 & & 1 \\
\hline 0.03 & 1 & 1 & 1 & 1 & & 1 \\
\hline 0.04 & 1 & 1 & 1 & 1 & & 1 \\
\hline $0.05^{*}$ & 2 & 2 & 1 & 2 & & 1 \\
\hline 0.07 & 2 & 2 & 2 & 2 & & 2 \\
\hline 0.10 & 2 & 2 & 2 & 2 & & 2 \\
\hline 0.13 & 2 & 2 & 2 & 2 & & 2 \\
\hline 0.16 & 2 & 2 & 2 & 2 & & 2 \\
\hline 0.19 & 2 & 2 & 2 & 2 & & 2 \\
\hline 0.22 & 2 & 3 & 2 & 2 & & 2 \\
\hline $0.25^{*}$ & 3 & 3 & 2 & 3 & & 2 \\
\hline 0.30 & 3 & 3 & 3 & 3 & & 3 \\
\hline 0.35 & 3 & 3 & 3 & 3 & & 3 \\
\hline 0.40 & 3 & 3 & 3 & 3 & & 3 \\
\hline 0.45 & 3 & 3 & 3 & 3 & & 3 \\
\hline 0.50 & 3 & 3 & 3 & 3 & & 3 \\
\hline 0.55 & 3 & 4 & 3 & 3 & & 3 \\
\hline 0.60 & 3 & 4 & 4 & 4 & & 3 \\
\hline $0.625^{*}$ & 4 & 4 & 4 & 4 & & 4 \\
\hline 0.70 & 4 & 4 & 4 & 4 & & 4 \\
\hline 0.80 & 4 & 4 & 4 & 4 & & 4 \\
\hline 0.90 & 4 & 4 & 4 & 4 & & 4 \\
\hline 1.00 & 4 & 4 & 4 & 4 & 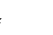 & 4 \\
\hline 1.10 & 4 & 5 & 4 & 5 & 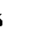 & 4 \\
\hline 1.20 & 4 & 5 & 5 & 5 & ; & 4 \\
\hline $1.25^{*}$ & 5 & 5 & 5 & 5 & 5 & 5 \\
\hline 1.30 & 5 & 5 & 4 & 5 & 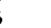 & 5 \\
\hline 1.40 & 5 & 5 & 5 & 5 & 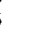 & 5 \\
\hline 1.60 & 5 & 5 & 5 & 5 & 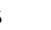 & 5 \\
\hline 1.80 & 5 & 5 & 5 & 5 & 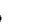 & 5 \\
\hline 2.00 & 5 & 5 & 5 & 5 & 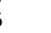 & 5 \\
\hline
\end{tabular}

* Concentrations are identical with those of the standard solutions
(1) low-not more than score 3 for either free or total coumarin, (2) bound-not more than score 2 for free coumarin and score 4 or more for total coumarin, and (3) free-score 3 or more for free coumarin and score 4 or more for total coumarin. It is recognized that the level of coumarin in second-ycar, field-grown plants at the time of flowering may be sufficiently high to necessitate a reduction in sample size in order to effect accurate differentiation of phenotypes with the standards used.

\section{The Paper Method}

Sheets of Whatman No. 1 filter paper measuring 6 by 9 inches were marked in 1 -inch squares and a piece of leaf approximating the size taken by a No. 1 cork borer was macerated with a small spatula or knife in the center of each square. In the laboratory, $2.5 \mathrm{~N} \mathrm{NaOH}$ was added to each sample on the paper. This addition was accomplished by means of a pipette with a capillary tip which was placed in contact with the sample during the addition. A volume of $\mathrm{NaOH}$ sufficient to make a spot approximately $10 \mathrm{~mm}$. in diameter, surrounding the sample on the paper, was used. Samples were immediately subjected to approximately five minutes of ultraviolet irradiation. Then, while the papers were still moist with $\mathrm{NaOH}$ solution, the samples exhibiting a bright yellowish-green fluorescence were classified " $F$," denoting an abundance of free coumarin. No score was given to samples having low fluorescence at this stage of the procedure.

Immediately after this initial scoring, the sample sheets were placed in an oven at $100^{\circ} \mathrm{C}$. $\AA$ heating period of 18 to 24 hours was usually used, although the time is somewhat flexible since some samples were clearly identifiable as bound after as little as 6 or 7 hours of treatment or as much as 48 hours. Following the oven treatment, a capillary pipette was used to moisten each sample with a small amount of water while irradiating with ultraviolet light. It is important to moisten a small area completely surrounding the plant sample without using an excess of water which tends to disperse the fluorescence over too wide an area. After irradiation for approximately $5 \mathrm{~min}$ utes, the coumarin content of the previously unscored samples was designated either as low (L) or bound (B), depending upon the absence or presence of fluorescence in the sample after oven treatment. Therefore, the three phenotypic classes identifiable with the paper method are as follows: (1) F-plants with a considerable amount of free coumarin as evidenced by strong fluorescence of the sample both before and after heating, (2) B-plants that contain bound coumarin but are very low in free coumarin as shown by the fluorescence which appears only after heating, and (3) L-plants that are low in both forms of coumarin as indicated by the lack of fluorescence both before and after heating (figure 1).

\section{Comparison of Tube and Paper Test}

A total of 365 greenhouse-grown plants representing 13 segregating $S_{2}$, lines were tested for coumarin content by both the tube and paper test. Samples for both tests were obtained from the same mid-leaflet, the apical portion being used for the tube test and a portion of the remainder for the paper test. The tests were scored independently. As indicated in figure 2 , the classification of plants by the paper method was in good agreement with that resulting from the tube method, although some differences were 
noted. Instances of disagreement are designated with asterisks in the figure. For example, 2 plants which were given scores of 2 for free coumarin and 3 for total coumarin and which, therefore, would have been called "low" by the tube test, were scored as $F$ by the paper test. Such cases of disagreement represented $3.3 \%$ of the total and were most frequent in the plants classified as $F$ or as $B$ by the paper test.

In a similar experiment in which 352 second-year plants were sampled on June 6 in the field, essentially similar results were obtained, as shown in figure 3 . In this experiment, cases of disagreement made up only $2.0 \%$ of the total and all of the plants for which there was disagreement were classified either as $B$ or as $F$ by the paper method. Because of a higher coumarin content of the free and bound phenotypes, the separation of coumarin-deficient plants from those containing coumarin was much more distinct for the field-grown material than for that grown in the greenhouse. The classification by the paper test of plants containing bound coumarin also was easier, possibly because of the greater amount of bound coumarin that was available for release by the oven treatment.

In another experiment designed to compare the quantitative assay method (4) with the rapid tube test, excellent agreement was obtained.

\section{DISCUSSION}

The rapid methods described above have several distinct advantages over qualitative methods described previously. Use of a scoring system involving standards with known concentrations of coumarin has greatly increased the accuracy and precision of the tube method of testing. In addition, separate detection of free and bound coumarin is possible in a single test, instead of requiring a combination of a

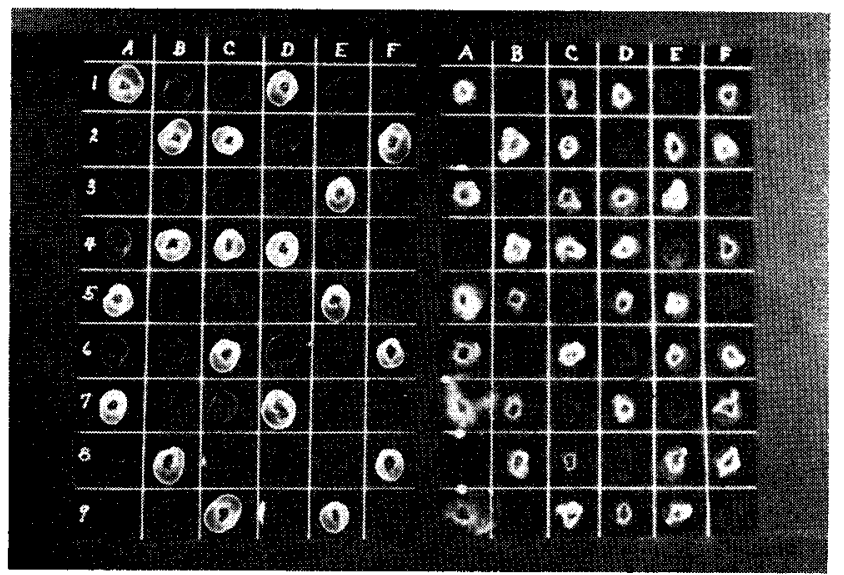

Fig. 1.-A demonstration of the filter paper test. showing an unheated sample sheet on the left and a duplicate sheet, after heating, on the right. Note the clear distinction of the samples containing free coumarin on the unheated sheet. A comparison of the two sheets permits separation of the bound and low coumarin samples. Samples classifed as free (F) are: A-1,5, $7 ; \mathrm{B}-2,4,8 ; \mathrm{C}-2,4,6,9 ; \mathrm{D} \cdots 1,4,7: \mathrm{E}-3,5,9 ;$ and $\mathrm{F}-$ 2, 6, 8. Samples classified as bound (B) are: $A-3,6,9 ; \mathrm{B}-$ 5,$7 ; \mathrm{C}-1,3,8 ; \mathrm{D}-3,5,9 ; \mathrm{E}-2,6,8$; and $\mathrm{F}-1,4,7$ Samples classified as low (L) are: $\mathrm{A}-2,4,8 ; \mathrm{B}-1,3,6,9$ $\mathrm{C}-5,7 ; \mathrm{D}-2,6,8 ; \mathrm{E}-1,4,7:$ and $\mathrm{F}-3,5,9$. Photographed under ultraviolet light with Royal Pan film using an exposure of seren seconds at $\mathrm{f} / \mathrm{s}$. short fluorometric method with a short colorimetric method. Simplification of testing for both forms of coumarin in a single test permits the wider use of the coumarin-conditioning alleles, $C u / c u$ and $B / b$, as markers in various types of genetic studies. Analysis of a single plant of unknown genotype, using either of the methods described, establishes the phenotype of the plant, while testing of $S_{1}$ plants establishes the genotype of the parental plant with respect to $C u / c u$ and also, in coumarin-containing plants, with respect to $B / b$.

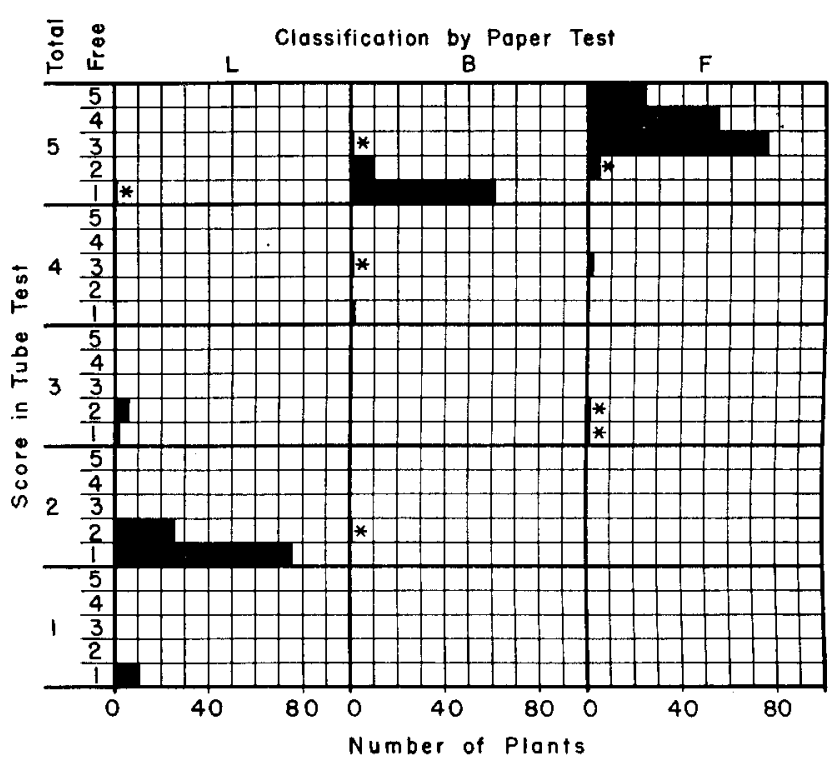

FIG. 2. Classification of coumarin content of greenhouse-grown plants analyzed with the paper test compared to the scores obtained with the tube test. Instances of disagreement between the two tests are marked with an asterisk

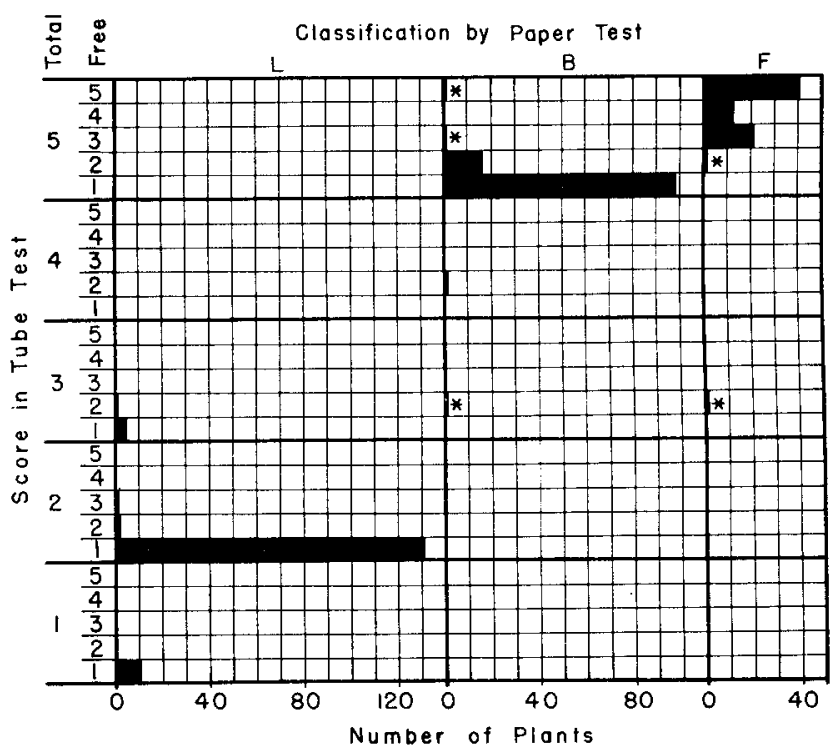

Fig. 3.-Classification of coumarin content of field-grown plants analyzed with the paper test compared to the scores obtained with the tube test. Instances of disagreement between the two tests are marked with an asterisk. 
In view of its lower accuracy but greater simplicity, it appears that the primary use of the paper test should be in initially screening large populations of plants. One operator can readily sample as many as 1,000 spaced plants in a period of 3 or 4 hours, while approximately 200 to 300 plants could be sampled for the tube test in the same period of time. The sheets of paper are easily handled in the field and a minimum of time is needed to treat the samples in the laboratory. Since free coumarin is somewhat volatile, it is desirable to treat the samples with base as soon as possible after sampling, although tests have shown that sheets can be stored in the dark at room temperature for at least 24 hours without serious loss of fluorescence. Once the samples are treated with base, they may be stored for extended periods. For example, samples on one such set of sheets can still be classified readily after the sheets have been stored in a dark room at room temperature for 15 months. A further advantage of the paper test is the elimination of the need for washing large numbers of tubes. A possible future use of the paper method might be as an aid to Crop Improvement Inspectors in checking for contamination in seed fields of coumarin-deficient varieties of sweetclover.

Following elimination of the majority of undesirable plants based on results from the paper test, the tube test could be used for more accurate classification of the remaining plants. The tube method also could be used initially in any study where greater accuracy was desired. For accurate analysis of a relatively small number of plants, the quantitative fluorometric assay method (4) should be utilized.

\section{SUMMARY}

Two rapid tests for free and bound coumarin in sweetclover are described. Of the two methods, the tube test is the more accurate since scoring is based upon visual comparison of the fluorescence of test solutions with the fluorescence of standards having known concentrations of coumarin. The method utilizes a small sample of leaf tissue autoclaved in water. Following removal of the leaf, addition of base, and irradiation under ultraviolet light, the sample is scored for free coumarin after which the solution is autoclaved, irradiated, and scored for total coumarin.

The paper method, suitable for rapid screening of large populations, involves maceration of a small piece of leaf tissue on filter paper followed by treatment with a small volume of base. After examination of the sheets under an ultraviolet light to detect "free" plants, the sheets are heated overnight in an oven, a small amount of water is added and the fluorescence is again classified. "Bound" samples fluoresce only after the oven treatment.

Experimental evidence pertaining to the accuracy of scoring in the tube test and the reliability of the paper test when compared to the tube test is presented. Possible applications of the methods are discussed.

\section{LITERATURE CITED}

1. Clayton, J. S., and Larmour, R. K. A comparative test for coumarin and melilotic acid in Melilotus species. Can. Jour. Res., C. 13:89-100. 1935.

2. Goplen, B. P., Greenshieldos, J. E. R., and Batenziger, $H$ The inheritance of coumarin in sweet clover. Can. Jour. Bot. 35:583-593. 1957.

3. —_. W and WhITE, W. I. Selection techniques in screening for coumarin-deficient sweet clover plants. Can. Jour. Bot. 34:711-719. 1956.

4. Haskins, F. A., and Gorz, H. J. The fluorometric assay of free and bound coumarin in sweetclover. Agron. Jour. 49: 493-497. 1957.

5. Slatensek, J. M., and Washburn, E. Roglir. A rapid, fluorometric method for the determination of coumarin and related compounds in sweetclover. Jour. Amer. Soc. Agron. 36:704708. 19.44.

6. Urer, Max. Ein Züchterisch brauchbares Verfahren zur Auslese coumarinarmer Formen beim Steinklee (Melilotus). Der Züchter 11:317-321. 1939.

7. Whitr, W. J., Savage, R. G.. and Johnston, F. B. A slightly modified fluorometric method of testing for coumarin content in sweet clover. Sci. Agr. 32:278-280. 1952. 